\title{
On Our Doorstep. Simmel, Weber and the Making of Reality
}

By Fabio D’andrea

University of Perugia

Introduction- Whether we like it or not, whether we believe it or not, 2020 will be the year that future historians will choose to mark as the advent of a new era. The pandemic did not simply hit us harder than any previous crisis - and God knows we had a few since the beginning of the XXI century! It left us disoriented and stranded, orphans of too many promises and proclamations, while showing us mercilessly the limits of our knowledge and the extent of our hybris, a mixture of inebriation and arrogance often found in Greek myths, where it leads heroes such as Icarus to ruin. The most powerful technology put to shame by an invisible... what? Thing? Living being? We just don't know, four words that we'd better keep in mind while reading the following pages.

The virus hasn't fit within our worldview right from the start and still there it is, paralyzing global economies and exposing the flaws and shortcomings of the neoliberal ideology. It makes it clear that no one survives on his/her own, that "free" markets bring forth indecent inequalities and scientists hold no definite truth, but argue and squabble about numbers and theories.

GJHSS-H Classification: FOR Code: 160899

Strictly as per the compliance and regulations of:

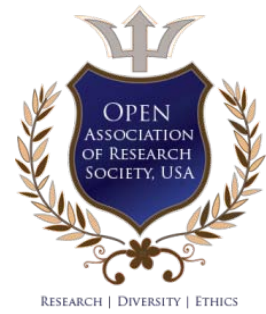

(c) 2021. Fabio D'andrea. This is a research/review paper, distributed under the terms of the Creative Commons AttributionNoncommercial 3.0 Unported License http://creativecommons.org/licenses/by-nc/3.0/), permitting all non-commercial use, distribution, and reproduction in any medium, provided the original work is properly cited. 


\section{On Our Doorstep. Simmel, Weber and the Making of Reality}

Fabio D'andrea

\section{INTRODUCTION}

W hether we like it or not, whether we believe it or not, 2020 will be the year that future historians will choose to mark as the advent of a new era. The pandemic did not simply hit us harder than any previous crisis - and God knows we had a few since the beginning of the XXI century! It left us disoriented and stranded, orphans of too many promises and proclamations, while showing us mercilessly the limits of our knowledge and the extent of our hybris, a mixture of inebriation and arrogance often found in Greek myths, where it leads heroes such as Icarus to ruin. The most powerful technology put to shame by an invisible... what? Thing? Living being? We just don't know, four words that we'd better keep in mind while reading the following pages.

The virus hasn't fit within our worldview right from the start and still there it is, paralyzing global economies and exposing the flaws and shortcomings of the neoliberal ideology. It makes it clear that no one survives on his/her own, that "free" markets bring forth indecent inequalities and scientists hold no definite truth, but argue and squabble about numbers and theories. Perhaps it makes it too clear, or at least too easily seen, and in so doing the virus offers a paradoxical excuse not to dig deeper. It allows us to go on believing that it is just another crisis, one we were almost waiting for and now that it is finally over it will be possible to put things right once and for all. As we say in Italy, "tutto andrà bene" (everything's going to be all right), a comforting if misleading statement. Among the skills in which humankind is at its best, there is the strange ability to look the other way when things don't go as they should (or you thought they should): Bob Dylan has been listening to the wind for almost sixty years now, but no answer came to the question about "how many times can a man turn his head / And pretend that he just doesn't see". So it would be easy to act as if there's nothing new and business will soon be back to normal. There's an irony to this virus, however: it sounds false to your own ears, even as you say it. This microscopic entity is epiphanic: it is and it is not, it forces you to believe and disbelieve, it makes you feel there is something wrong with the way things have always been. By crashing the old, sanctified aut/aut mechanism by its simple existence and its all-too- complex consequences, the virus goes well beyond any practical issue and undermines the very patterns within which the idea of "practical" makes sense.

Sars-CoV-2 is an epistemological virus as well. From this standpoint it stems from a culture broth that has been brewing for some time, an awkward awareness that what looked like a paradigm shift could be something more than that, even though - truth be told - we don't know what living within an actual paradigm shift might be like. We think we know, but in an abstract way, as we never thought we'd have to face such an event: after all, we devised the best knowledge, the perfect knowledge, the objective discourse on reality that could not falter nor fail us, so how could we ever imagine that we would find ourselves groping for meaning in a world suddenly alien and unrecognizable? Still, we reckon that it must be something that has to do with change, a wide and perhaps cataclysmic rearrangement of values and institutions, of priorities, that would have to happen within the same main frame of understanding, because it is the only existing frame. Some thinkers do not quite agree; others have been made to agree up to now, but that could be over. As Beck writes, we need to «introduce the distinction between change and metamorphosis or, more precisely, between change in society and metamorphosis of the world. Change in society, social change, routinizes a key concept in sociology. ${ }^{1}$ Everyone knows what it means. Change brings a characteristic future of modernity into focus, namely permanent transformation, while basic concepts and the certainties that support them remain constant. Metamorphosis, by contrast, destabilizes these certainties of modern society. It shifts the focus to "being in the world" and "seeing the world", to events and processes which are unintended, which generally go unnoticed» (2016, p. xi).

This essay will try and explore the possibility of this shift, the preconditions of its thinkability, addressing some "certainties" that had better be given some leeway. It will do so with the aid of two fathers of sociology, Georg Simmel and Max Weber, who went well beyond the limits of standard thinking and paid a price for it. It is not by chance that both are being rediscovered: regarding Simmel, we are witnessing what can be called a «Simmel Renaissance» (De Simone,

\footnotetext{
${ }^{1}$ This essay was produced with the support of the «Fondazione Cassa di Risparmio di Terni e Narni» (CARIT).
} 
2002, p. 11), after long years of plunder and neglect; regarding Weber, it is more a change of perspective that makes some hallowed themes lose their shine, while others come to the fore, their importance easier to notice a century later. 2020, among other things, is the centenary of Weber's death, thus the right time to start following some fascinating leads he has left behind. A combined reading of Simmel's Bridge and Door and Weber's particular definition of culture will be an apt starting point to pose a few questions that have been skirted so far: how do we manage to create the «finite section of the meaningless infinity of events in the world" (Weber) that we live in? Is it something we consciously plan and build or has it to do with other processes and dynamics we might even be unaware of?

In those beautiful texts, we will find that both authors share the same view of culture as an instituting act, creating an island of meaningfulness within the perpetual flux of the Becoming of the world. This region, reality, is apparently separated from the rest: it is however a trick of the eye, because only a constant exchange between the inside and the outside can assure the former the semblance of stability humankind needs to feel at home and prosper. So we will turn to one of Simmel's key concepts - Wechse/wirkung, reciprocal action - to see if it can help us better understand this enigmatic to-and-fro and we will highlight its strong connections with Goethe's Anschauung and with the most recent discoveries of quantum mechanics. We will then put forward a hypothetical reason for the lack in Western thought with a few significant exceptions - of any sensibility to the idea of process, briefly exploring the imaginal drive to the quest for a fondamentum inconcussum, a quest that brought us, ironically, to the discovery of the destabilizing subatomic universe. A dynamic perspective on reality undermines this very need for stability at all costs, as will be shown by going back to Weber and extending his definition of culture to include the "new" role of reality caretaker that is its necessary consequence and complement. Taking stock of new discoveries issuing from anthropology and philosophy, we will finally consider the possibility that it mainly comes down to processes that «are unintended [and] generally go unnoticed». The stuff of reality might be far more entangled and subtle than we guessed so far.

\section{Through the Hidden Door}

We will set out by following one of Simmel's "minor" texts, an essay so short as to be little more than a fragment, infrequently translated, and for which interpretations so far have been mainly aesthetic: Brücke und Tür, Bridge and Door (Simmel, 1997). In its rapidly-sketched ideas and the quasi-immediacy of a Zen story, we can find useful elements for understanding the enigmatic dynamic we are approaching. It is also a good example of Simmel's technique, which exploits as far as possible the semantic ambiguities of words and what we might define as the fade-out between the signification levels of a term, that is the colouring of acceptations of a word in hues belonging to its other meanings. This is also a little-investigated mode of Wechse/wirkung, which could be set at the basis of a new method - terminological multisignificance - to which we will have recourse in these pages, convinced as we are that this "bastard speculation" is one of the instruments of choice in sociological thought.

This essay is apparently a discussion on the aesthetic value of the "bridge" and the "door" as objects portrayed in painting. With regard to the former, Simmel poses an introductory parallel with the portrait and then observes: «The bridge confers an ultimate meaning elevated above all sensuousness, an individual meaning not mediated by any abstract reflection, an appearance that draws the practical purposive meaning of the bridge into itself, and brings it into a visible form in the same way as a work of art does with its "object"» (Simmel, 1997, p. 172). This last sense, «elevated above all sensuousness» - please note the paradoxical turn of phrase - is the sense of Life, comprehensible only through the intuition that goes beyond language and can be expressed through the miracle of Art, «when it puts the spiritually gained unity of the merely natural into its island-like ideal enclosedness" (Simmel, 1997, p. 172). The bridge stresses the human capacity to unite, to reach a synthesis of the enormous meaning of reality; the capacity, however, that Simmel has already defined as being inseparable from the other opposite and complementary capacity to divide: "Only to humanity, in contrast to nature, has the right to connect and separate been granted, and in the distinctive manner that one of these activities is always the presupposition of the other» (Simmel, 1997, p. 171).

Whereas the bridge immediately indicates man's ability to link things up, in the same way the door indicates the interdependence of the two activities: «The door represents in a more decisive manner how separating and connecting are only two sides of precisely the same act. The human being who first erected a hut, like the first roadbuilder, revealed the specifically human capacity over nature, in so far as he or she cut a portion out of the continuity and infinity of space and arranged this into a particular unity in accordance with a single meaning» (Simmel, 1997, p. 172).

The discourse moves away from the initial aesthetic approach. Simmel's ideas follow two different intuitions at the same time, moving imperceptibly among sense levels in showing that the complexity, the polysemanticity of language gives us ways to approach, on equal terms, the complexity of the real, in which man hardly ever finds one single meaning, however much he 
holds rationally that this is how things are. In order to clarify the diverse bearings of Simmel's words, we may compare them with Weber's description of culture already mentioned: "Culture" is a finite section of the meaningless infinity of events in the world, endowed with meaning and significance from a human perspective [...]. The transcendental precondition of every cultural science is not that we find a particular, or indeed any, "culture" valuable, but that we are cultural beings, endowed with the capacity and the will to adopt a deliberate position with respect to the world, and to bestow meaning upon it» (Weber, 2012, p. 119).

The two statements harmonize almost exactly so we may easily hold that «the specifically human capacity over nature» should not be recognized in science and/or technology as a superficial reading might suggest, but in culture, hence in the capacity and will «to adopt a deliberate position with respect to the world, and to bestow meaning upon it». Whoever acts culturally carves out «a finite section of the meaningless infinity of events in the world» and shapes it «into a particular unity in accordance with a single meaning". Acting culturally therefore means building a house and opening a door in the wall.

When the first house was built «a piece of space was thereby brought together and separated from the whole remaining world» (Simmel, 1997, p. 172). The cultural act presupposes an interior, a familiar, inoffensive environment wherein to find refuge from looming uncertainty, conferring upon it a coherence constructed upon a profound set of choices and values; yet at the same time it presupposes an exterior. However, unlike what we might think in the light of the either/or paradigm, the latter is in constant complementary relation with the interior: "By virtue of the fact that the door forms, as it were, a linkage between the space of human beings and everything that remains outside it, it transcends the separation between the inner and the outer. [...] The door speaks. It is absolutely essential for humanity that it set itself a boundary, but with freedom, that is, in such a way that it can also remove this boundary again, that it can place itself outside it» (Simmel, 1997, p. 172). That cultural move cancels the sense of distinction between interior and exterior since, like fashion, it both brings together and separates, thus satisfying the contradictory and contrasting needs disquieting the human soul: «The finitude into which we have entered somehow always borders somewhere on the infinitude of physical or metaphysical being. Thus the door becomes the image of the boundary point at which human beings actually always stand or can stand» (Simmel, 1997, p. 172).

The door is therefore a boundary between worlds, the slender blade of the Sword-Bridge of Arthurian legend, Nietzsche's "Schwelle des Augenblicks". It is the point where common sense is revealed as that to which «we have become inured [...] through daily habit», and from which man may eventually feel «the wonderful feeling of floating for a moment between heaven and earth» (Simmel, 1997, p. 173). It is the moment when man becomes conscious of the primordial conventionality of culture, and the reference to mythological tradition is no coincidence. Almost all those who have in any guise had dealings with such dynamics recognize the difficulty of the gesture of opening out towards the possible, of driving oneself to the limit; they also recognize that not everyone wishes, or is able, to do it: only heroes are destined to confront the Sword-Bridge and even they are not all capable of crossing it. Simmel knows this and that is why he reminds us that man "can stand» on the threshold. If he so desires. If he is able.

The act which postulates an interior within which to withdraw from the threats outside presumes a door without implying the need to open it; indeed, in order to effect this task of reassurance, it must act "as if" the door in question did not exist. It must forget the ethical, cultural, human process which led to the initial selection, the first attribution of sense, and attribute to the «tiny part of the individual reality that we observe at a given time $[\ldots]$, coloured by our interest, which is conditioned by those value ideas" and "alone has significance for us» (Weber, 2012, p. 116), a tone of naturalness that suppresses the ever-present doubt that it may indeed be exactly what it is: an arbitrary construction, a powerful instrument to react against the anguish each one of us feels at being cast into the world (Crespi, 1989; Jedlowski, 1994), a world whose very sense is utterly incomprehensible.

Outside the door is the infinitely possible, everything that culture has excluded from common perception, yet its final sense is also there, since it may even crystalize in a Form, but «its limitedness finds its significance and dignity only in that which the mobility of the door illustrates: in the possibility at any moment of stepping out of this limitation into freedom» (Simmel, 1997, p. 172). As we know, setting a limit is profoundly human, but so is holding on to the chance of getting rid of it, of going beyond. It is the on-going tension between these two needs that constitutes humanity. In Simmel "man" - in contexts of this type - should be interpreted as the "accomplished subject" in an almost heroic sense, that is to say the subject who has successfully achieved the work of realizing his own identity, the Bildung. This is the same man Weber has in mind, possessed of «the capacity and the will to adopt a deliberate position with respect to the world, and to bestow meaning upon it». Although we will have to return to the issue with a critical eye, it appears as central since the task both authors assign to man is to doubt the unique nature and the stability of his own common sense and so to risk giving up the unconscious, automatic support it guarantees. In order for that to be possible, Simmel maintains, the subject 
must have within himself the measure of things, he must be able to rely on the foundations he has granted himself with his subjective culture (D'Andrea, 2019) and not only on those he shares with others. Like Marx, like many others, Simmel understood the melting into air (Berman, 2010) of the substance of the social, its becoming more and more a flux, a process. He even glimpsed its implications both positive and negative for the life of man, with no a-critical enthusiasm, and towards the end of his life he turned to pedagogy, convinced of being able to bestow upon young people the instruments necessary to face the new challenges (Hauter, 1922). Thus he clearly showed that he believed that the difficulty of the cultural gesture is not necessarily the source of desperation and paralysis, but lends itself to experience in different forms: this gesture, with adequate preparation, may lead to a wide assortment of stances, ranging from a critical awareness in everyday life up to the acceptance of the Law of the Individual (Simmel, 2010, pp. 99-154) that enable subjects to withstand the impact of a changing world and to turn it in their favour.

However, for this to happen we need a better understanding of the dynamics of the gesture, or rather of the process of cultural co-creation, in order to realize how active the role of a "simple" member of a society is and how vast its implications are. The movement linking the interior and the exterior as defined by the Door is well described by Simmel's Wechse/wirkung, reciprocal action, which we have so far considered rather too much in the light of the current mechanistic paradigm; through its filter we have read Wechse/wirkung as an exchange as yet mechanical, something that constructs a link between individuals that must be in any case interpretable in the light of reason, instrumental and economic. We have highlighted the pioneering emphasis on retroaction - which in cybernetics will become feedback - underlining how its context accommodates the case of linear causality while depriving it of the primacy it holds in today's engineered world: «The term [Wechse/wirkung] indicates a concept of reality (in general, not merely social) as the network of reciprocal relations of influence among a plurality of elements $[\ldots]$. If we isolate one single relationship from the network of relations (for example, the relations between $A$ and $B$ ) and if in such relations we consider, time by time, one single direction (the effect that A produces on B) we can speak of the causation relation of $A$ on $B$. From this it is clear that: a) the concept of reality as a reciprocal action between elements does not exclude the use of the causality category and the analysis of the relation in terms of causal relations, even if their ambit of application is circumscribed; b) the reciprocal action leads to a processual analysis which involves considering the time dimension and the application of the retro-action category» (Cavalli, 1998, p. xvi).
Cavalli takes great care to reconcile the main element of modern vision - simple linear causality - with Simmel's outlook, making a specific case for it (relevant precisely because of this specificity) within a wider picture that implies the processuality inherent to society and the reciprocity of actions. Within the very style of the explanation, there does however remain a "scientific" tone that limits the innovative, subversive potential of Simmel's vision. More recently, Scaglia has returned to, and underlined, a further aspect of the diversity of the Wechse/wirkung, focusing on the scale of the relations it brings about. Envisaging the dichotomy between the atomic, Einsteinian world and the subatomic, quantic world, Simmel writes: «lt is only a superficial attachment to linguistic usage (a usage quite adequate for daily practice) which makes us want to reserve the term "society" for permanent interactions only. More specifically, the interactions we have in mind when we talk about "society" are crystallized as definable, consistent structures such as the state and the family, the guild and the church, social classes and organizations based on common interests. But in addition to these, there exists an immeasurable number of less conspicuous forms of relationship and kinds of interaction. Taken singly, they may appear negligible. But since in actuality they are inserted into the comprehensive and, as it were, official social formations, they alone produce society as we know it. To confine ourselves to the large social formations resembles the older science of anatomy with its limitation to the major, definitely circumscribed organs [...] and with its neglect of the innumerable, popularly unnamed or unknown tissues. Yet without these, the more obvious organs could never constitute a living organism» (Simmel, 1950, p. 9).

«These are the minimal relationships, » Scaglia comments, «that chain together the atoms of society, to guarantee the force of both the cohesion and the elasticity of social life, of its coming about» $(2010$, p. 13). The apparent, the visible, merges and is constituted in the unperceived, the generating, unifying invisible, just as the appearance of "greater" reality is triggered by dynamics and bonds which we are starting to grasp, but which overturn the usual patterns with which the wealth of the real has so far been reduced to a reassuring, manageable quantity. Simmel's words also show awareness of the characteristics and limitations of the "normal" cognitive strategy of science and the recognition of a succession of stages within it, in the direction of the awareness of a complexity until then refused, in which - in a brave effort of reconstruction the qualitative aspect appears once more: like connecting tissue, without which there could be no organism, so the countless Wechse/wirkungen have «the task of expressing and sustaining "all the color and consistency of social life, that is so striking and yet so mysterious" [...]. Simmel states that should sociology 
fail to analyse these processes it would deprive itself of the possibility of knowing those social dynamics "which only the marvellous non-tearability of society can open, that is to say the fluctuation of its life, through which its components incessantly grant it its stability, lose it or defer it» (Scaglia, 2010, p. 13).

Simmel's comment on the topic of connecting tissues, unknown to «the older science of anatomy», also presents the opportunity to criticize one of the fundamental hypotheses of Modernity, the possibility of the accumulation of knowledge until the perfect comprehension of the universe is inevitably achieved. This illusion, still propping up a good deal of commonlyheld sense as regards science and technology, is in fact a betrayal of the original scientific spirit which is more recognizable in the proposed, widespread acceptation of the idea of the «falsifiability" of theories as advanced by Popper (1959). ${ }^{2}$ The loss of the humility that should be a feature of anyone devoted to research is often a source of error. Forgetting that we are not (cannot be) omniscient ends in neglecting the importance of what has not yet been understood and in making statements which, although later denied, become part of the shared social discourse - itself hardly aware of the real dynamics of knowledge - and lead to expectations upon which follow disappointment and frustration.

Let us return to Wechse/wirkung and the need to widen its scope. In order to understand it better we may usefully have recourse to Goethe's idea of Anschauung, vision. A deceptively familiar term, the way in which it is now understood is one of the cornerstones of the modern framework: as Sirost observes, «the advent of the panoptic indicates a prevalence of sight in the new hierarchy of the senses. In the different interpretations, the subsumption of the senses to vision marks the superiority of modern man, the canalization of the many sensorial stimulations or the imposition of a cultural habitus» (2005, pp. 122-123). This is an excellent rationalization strategy for the imaginal valorisation of the sense of sight, which has since the dawn of time manifested strong links with the spirit, the immaterial, distance, control and knowledge, so much so that one of the most common symbols of the divinity is the Eye in the sky, for the ancient Egyptians as for Christians. It is a contradictorial sense, since it implies both separateness and an intimacy otherwise unobtainable: to look at each other, there is no need for physical contact, yet the eyes are the mirror of the soul, the highway for recognition and for expressing emotion. Modernity has willingly done away with this dimension, preferring control and dominance - Orwell's Big Brother points the way!

In this perspective even the co-relation with thought is meaningful and has been relevant since the start of the scientific Revolution. One of the founders of the Royal Society, John Wilkins, writes in his Mercury, or

\footnotetext{
${ }^{2}$ For a more detailed account of the question, see D'Andrea, 2017b.
}

the Secret and Swift Messenger of 1641 that «there is nothing (we say) so swift as Thought» and Gleick notes: «Next to thought, the swiftest action seemed to be that of sight. As a clergyman, [Wilkins] observed that the swiftest motion of all must belong to angels and spirits [...]. The rest of us, stuck with Organical Bodies, "cannot communicate their Thoughts so easie and immediate a way"» (2011, p. 168). Spirit/Thought, sight and speed are inextricably connected in the melting-pot of ideas and theories from which Modernity was born: our culture is built on the exclusive paradigm of separation and it is no coincidence that sight is one of the senses with which we are most at ease since it is the instrument of distance and it is through distance that we separate ourselves from the world. Yet this is not the sight Goethe and Simmel had in mind: Anschauung, in its strong sense, is something that goes well beyond: it is something that causes a profound, almost physical, interaction with the object and it breaks apart its very category. It breaks apart the absoluteness of the dichotomy and brings about one of the focal points in Goethe's reasoning which, through the recovery of the contradictorial feature just mentioned, intended to return process and form to their complementary nature: «This key term [Anschauung] encapsulates Goethe's way of "seeing" the object of study; a way of engaging with it that includes looking-at, gazing, contemplating, seeing beyond, beholding, perceiving the core, intuitive apperception, establishing an intuitive bond. It overcomes the subject-object division, on which modern natural science is predicated, through the subject's full participation in the Oneness of Nature» (Bleicher, 2007, pp. 144-145).

Anschauung is a vision implying a constant attempt to overcome the distance between us and the object, it is a being-with the object capable of generating intuitive knowledge, it is something that goes beyond. Up to today we have not been able to appreciate this level of complexity and interaction since our cognitive instruments have a priori excluded it, although it is the result of a current of thought rightfully entitled to belong to Western culture and which is perhaps only waiting to be rescued from the heap of ruins lying at the feet of Benjamin's Angelus Novus, repaired and handed down to a new modernity.

In an attempt to better understand this rather unusual outlook, it may be useful to go back to Heisenberg and his famous Principle of Indeterminacy which affirms the impossibility of knowing the data of a quantum system without disrupting it: «In virtue of Heisenberg's Principle of Indeterminacy, we cannot determine both the position and the speed of an electron simultaneously, given that precision in measuring one nullifies that of the other. This happens because the process of laboratory measurement upsets the particles themselves: we thus have an indissoluble interaction between observer and the reality observed" 
(Teodorani, 2007, p. 7). In other words, on the basis of this principle we can state that the act of observing is not neutral and that observation modifies reality; therefore, in a certain sense, it empirically confirms Goethe's Anschauung theory, and this did not escape Heisenberg's notice; in a speech in the Seventies, he cited not by chance the great scholar and recalled his warning: «The natural sciences and art have moved in a direction Goethe had warned against [...]. Natural science has taken the step into abstraction [...] and advanced towards the Urgebilde (primordial structures) in biology and the Urformen [...]. At the same time, the dangers have become as threatening as Goethe anticipated. If we think of the increasing soullessness, of depersonalizing labour, the absurdity of modern weapons systems, or the flight into delusion that has taken the form of a political movement» (as cited in Bleicher, 2007, p. 153).

His mention of Goethe is an integral part of a reflection on the range, not only scientific, of the new frontiers in quantum physics; like some of his other colleagues, the German physicist is an example of a scientist who could be defined "Goethian" in not confining himself to his own specific, narrow disciplinary sphere, but pondering upon its consequences throughout wider culture, assessing them philosophically and devoting himself in the first person to the needful, praiseworthy task of divulgation: «Since it is true that the results of modern physics do touch such fundamental concepts as reality, space and time [...], it may not be an unimportant task to try to discuss these ideas of modern physics in a not too technical language [...].The best way to enter into the problems of modern physics may be by a historical description of the development of quantum theory. It is true that quantum theory is only a small sector of atomic physics and atomic physics again is only a very small sector of modern science. Still it is in quantum theory that the most fundamental changes with respect to the concept of reality have taken place» (Heisenberg, 1958, p. 28).

Heisenberg's words show how the attempt to confine theoretical problems on quanta to subatomic reality while leaving intact the discourse on "greater" reality is equivalent to the initial dealings with the unconscious, after Freud had revealed its existence: it may be there, but with no effect on normal, rational life, something exotic for us to play with while not making much difference. Accepting theoretically what cannot be disproved yet depriving it of any practical relevance is a consolidated strategy in the modern paradigm. With his second a priori, Simmel took on the responsibility of denying the sterilization of the inner world, declaring its importance in the evolution of social and relational processes (D'Andrea, 1999, pp. 90-94). Today we may perhaps take one step ahead, better illustrating his processual and interactive vision of the social and even extending its range.

\section{Reality as a Process}

For this to happen something more must be said about the idea of our world issuing from a constant flux, a cosmic process from which humankind somehow manages to create and maintain a solid-seeming sphere wherein to live and find shelter, the Weberian «finite section». A new way of thinking requires changes and reshaping of the use of the instruments available, and of the understanding of their foundations; we do not generally wonder about the latter because «as long as we live wrapped up uncritically in the naïve, natural attitude of life and restrict ourselves to the public, general interpretation of the world, which is given to us in advance through common language and tradition in the broadest sense, we "know" who we are, what our task and our goal are, what duty and right, custom and law are» (Fink, 2016, p. 44). The problem about this "knowing" is that it proves firm and reliable only under a superficial glance or in its acceptation as obvious and "natural": "As soon as one contemplates, the commonplace certainty of the immediate interpretation of the world vanishes. When the lightning bolt of wonder strikes us, mysterious amazement bursts open, for which everything familiar suddenly becomes unfamiliar and questionworthy [...] [If] the contemplativeness of thought comes over us we fall from former certainties; we no longer know who we are, what a human being is, what custom and right, thing and world are» (Fink, 2016, pp. 44-45).

This is probably why Wittgenstein, discussing certainty, stressed the importance "of the ability not to doubt with respect to the validity of the assumptions that belong to the [language] game itself, as it is played by the members of a community» (Jedlowski, 1994, p. 47). Jedlowski's further analysis on the subject of not doubting is interesting: he observes that it may perhaps correspond «yet more to the ability to ask the right questions than to the faculty of believing in the "right" answers to any questions that may come up" (Jedlowski, 1994, p. 47). It is not only a matter of relying on what we are told, we also need a certain degree of competence in avoiding certain questions which risk dismantling the habitual "knowing" of which Fink speaks, thus plunging the questioner into «mysterious amazement». Here we find a double register to which we must pay attention: on one hand the "certainty" of daily knowing, freely and surely; on the other the bewilderment coming from the courage to ask "senseless" questions (Jedlowski, 1994, p. 48), which though devastating in a certain sense - save us from a mistake that may prove fateful: "The ability to ask these questions is essential. Their complete obliteration would in fact correspond to total acceptance, in each one, of the world just as it is, thus definitively renouncing the potential to think otherwise» (Jedlowski, 1994, p. 49). 
Our culture seems to have devoted too much care to the first register, neglecting and then definitively banning that second, destabilizing one which cuts the ground from under our feet. The desire for a secure basis is one of the features most profoundly characterizing our civilization, distinguishing it from Oriental civilizations: «Most modern philosophy, according to William Bartley, can be re-interpreted as the search for a fondamentum inconcussum, i.e., the search for an authority or a decisive criterion to appeal to in order to justify our own ideas and proposals" (Reale and Antiseri, 2001, p. 51). I have no doubt that there is a level of justification in the light of which this dynamic seems to fall within normal power games, where such a criterion seems fundamental; however, as in many other cases within our culture, I believe that it is a derivation - in Pareto's sense - aiming to render rational and acceptable an urgent need which is neither one nor the other (D'Andrea, 2017a), deriving instead from the metaphysical bewilderment consequent upon the condition of «being cast into the world», as Heidegger put it. Yet this is only one of the ways in which it is possible to interpret one's own being in the world, consistent with the frustration and terror of Plato's charioteer at finding himself imprisoned in a body of mortal, perishable flesh. As Bachelard remarks, «before he is "cast into the world," as claimed by certain hasty metaphysics, man is laid in the cradle of the house. And always, in our daydreams, the house is a large cradle. A concrete metaphysics cannot neglect this fact, this simple fact, all the more, since this fact is a value [...]. Being is already a value» (1994, p. 7). This different vision connects better with the sense of wholeness and protection attributed by Simmel to the founding act of building a house: to the fundamental generation of sense that this brings about, it adds an equally crucial pre-rational, emotional note and integrates the value of being within the multidimensional complexity. It thus retrieves a substance and a dignity of which the current instrumental and economistic vision has lost sight.

Yet it would appear that in the Western view, Being is a value only when endowed with robust, permanent foundations. It is no coincidence that at the root of the various decisive criteria listed by Antiseri (Reale and Antiseri, 2001, p. 52) lies the criterion thanks to which they find objects and ways with which to construct justifications and which is founded precisely on the stability in space and time that becomes immobile eternity: "The hierarchical relation of things is initially asserted pre-philosophically according to some distinction of power, beauty, or the like, and then philosophically interpreted with regard to constancy in time, strength of Being, and rationality, whereby what is most continuous and most rational counts as most being» (Fink, 2016, p. 55). The troublesome point is to choose the interpretative criteria which guide philosophical reflection, as they do every other human intellectual initiative; in the West it has seemed obvious, "natural", that the value of the entity should be linked to its immutability, which means eternity, but also to immobility. ${ }^{3}$ The positive accent on structure is thus revealed to be inscribed within the imaginal nucleus of our paradigm, since it embodies exactly those features of solidity and permanence that are at the base of the construction of the whole edifice of our culture (episteme is etymologically "what stands up by itself", hence is capable of serving as the foundation for the rest, the certain, incontrovertible knowledge of the causes and effects of becoming). This need to be rooted - which is nothing but a naked, agonizing search/plea for sense - has however unexpected consequences, being self-unaware and repressed; if it were not, it would reveal the weakness and undermine the credibility of the triumphalist story culminating in modern Progress: «What is more profoundly questionworthy is whether that from which the ontological status of all existing things is determined would itself have to be a highest being, whether it as summum would have to be an ens. If philosophy determines the hierarchy from a relation of things to a highest being, then this hierarchy, however much it is held to be problematic, nevertheless fundamentally has an intraworldly character. The ontological status of all things is determined from the relation to a being that is just as much "in the world" as they themselves are" (Fink, 2016, p. 56).

The primordial choices that founded the Western paradigm, dictated by imaginal anxiety rather than by rational awareness, lead to the staging of a stable, solid world, the ultimate outcome of which will be a separate, indifferent objective reality, and such choices reduce everything to an «in the world» relationship. To go back to Weber, this is equivalent to absolutizing the "finite section» and rescinding that founding bond which, as we saw regarding Simmel's Door, every culture has to maintain with whatever remains outside it, lest it "gain" that immobility so hotly pursued and a fatal closure, the opposite of what would allow us to rectify the request for essential sense. Opening up to relations and flow, not shutting ourselves up behind walls - and just think how terribly topical that is today! - allows some relief from the metaphysical anguish; opening up to the becoming of the world, whether we assign whatever sense we can to it or else we accept its unfathomable otherness, is the condition on which we are able to continue being creative, poetic in the high sense of the word, but this also means recognizing that otherness and the fact that it is not subject to our

\footnotetext{
${ }^{3}$ This may be one of the profound reasons why movement cannot seem to fit into either philosophical or scientific thought, and it is a further fundamental component to be reintegrated into a complex model of humanity. See Sheets-Johnstone, 2011.
} 
wishes. It is a delicate step, since in part at least it nullifies the claims for control and management of the existing on which the tale of Modernity is founded and further back the imaginal strife of the Western paradigm: this is why the thought of flow and movement has never been popular in our culture, although it has continued to surface along its way to seek acceptable forms of expression such as Simmel's Door or Weber's finite section.

The first, immense thinker who glimpsed the cosmic dance and sought instruments fit to put it into words (he was not called the Obscure without reason) was Heraclitus of Ephesus, at the dawn of philosophy, who claims: «Of all whose discourses I have heard, there is not one who attains to recognizing that the wise is set apart from all» (Colli, 1993, p. 33). The creating knowledge implies being aware of the outside and the intuition of the fact that it is from the relationship with the outside that things acquire sense and existence; we access this knowledge only in part, with difficulty, yet we manage to draw our world from it. Heraclitus calls this moulding, generative instance pyr, Fire, which, as Fink observes, «does not mean that out of which all things exist, but rather the arranging power that strikes all individuated beings with the character of a beautiful, gleaming total dispensation» (Fink, 2016, p. 50). ${ }^{4}$ It is process and order, it is creation and destruction, and going beyond the either/or paradigm's potential to settle things, it escapes us, so that we see only one side of it: order, which by itself leads to paralysis; destruction, which in our secular cosmogony has taken the form of entropy. Its unilateral accentuation, typical of our scientific vision in the form of the Second Principle of thermodynamics, is revealed as another figure of anguish invoking the fondamentum which we try to drive out the door, but which returns through every window. Of a completely different imaginal stamp, the search for a Second Law capable of describing the pars construens (Holland, 1996; Kauffman, 1995) and overcome the limits of the paradigm - thus opening up to Morin's self-ecoorganized system (1993) where life and death, firing up and extinguishing cohabit incessantly - is a further sign corroborating the rise of new cognitive constellations, but it too requires suitable theoretical frameworks and the courage to face the bewilderment that «senseless questions» bring with them.

\footnotetext{
${ }^{4}$ The idea of a separated «arranging power» has strong connections both with Oriental thought and contemporary quantum physics, which are much closer than most would think, as Capra (1975) noted a few years ago. This is especially the case with Bohm's recent theory of an implicate order (1980), that seems to give a new, scientific look to the Ephesian's intuition.
}

\section{The Idea of the ReAL}

In this new frame of understanding some measure to re-establish a balance among the deep desires that, according to Saint Augustine, drive the human adventure in the world would be required. Augustine speaks of three libidines: libido dominandi, libido sciendi and libido sentiendi. The first is the easiest to interpret: thirst for power and dominance; the second aims at knowledge for its own sake; and the third touches upon the joy that comes from understanding. They are normally intermingled, at both subjective and cultural levels, but the present mix tends strongly towards an alliance between libido dominandi and libido sciendi, with the latter pushed into second place. All libidines should instead be equally important to begin to assess the true scope of the cultural enterprise, as we have seen it through Simmel's and Weber's insights. The current paradigm hinders this, however, since such re-balancing would mean giving up the promise of control and certainty on which it has constructed its long domination, even though this promise has shown itself illusory and unfounded: «We had to await the events of the second half of the twentieth century to learn what Socrates meant by his puzzling statement "I know that I know nothing". Ironically, our continually perfected scientific-technological society has granted us the fatal insight that we do not know what we do not know. But this is precisely the source of the dangers that threaten humanity» (Beck, 2009, p. 47). Modern arrogance is being undermined by the healthy caution of those who find themselves once more constrained and without guidance in a universe of which they know a good deal but not enough, with the aggravation - so to express it of having no idea of what they do not know. The rephrasing of Socrates's saying is radical: no longer a quantitative issue to be remedied through discoveries and scientific progress, it is rather an issue of the quality of knowledge, which shows itself as a set of vistas out onto an incomprehensible overall reality; vistas which throw light on certain aspects but leave others - how many? which? - more or less in the dark, indeed at times without the faintest glimmer of light. "I know that I cannot know" is probably the new form of those old words.

The fact that this way of thinking may seem utterly alien to Western tradition merely goes to show the efficacy of the discourse so far prevailing. Its roots are firmly within the same culture to which we owe cognitive exceptionalism, a culture rich and well-structured in alternative visions often incompatible with one another. Only continual simplification - today reaching levels of vulgarity unthinkable only a few years ago - can possibly present it as monolithic and consistent, in the glorious isolation of the Superior against all and everyone. What is called the culture and the vision is only one culture and one vision among many, although 
materially it has proved incredibly successful: and we are all about to pay for it. Initially however, when this constellation emerged from the far-flung stars, the figures who were to become referential in the Scientific Revolution had different opinions on the extent and potential of the new method of investigating reality. Newton, who considered himself more of an alchemist than a scientist, might have inspired Morin's outlook on uncertainty: «We should teach strategic principles for dealing with chance, the unexpected and uncertain, and ways to modify these strategies in response to continuing acquisition of new information. We should learn to navigate on a sea of uncertainties, sailing in and around islands of certainty" (Morin, 1999, p. 3). The idea of knowledge as an archipelago of solid, trustworthy notions is nearer reality than the illusion of objective truth and is the constant counterpoint to the misleading story of the modification and dominance of the world. It is an archipelago and an ecosystem where different branches of knowledge cohabit in relations of exchange and coevolution, instead of each shutting itself up behind its own fences and holding all the others in contempt. The danger of such a situation and its consequences have already been described through Heisenberg's words in his speech recalling Goethe, from which it is evident how close the correlation is between the way of carrying out knowledge-creation processes and the rest of society life: work, weapons, political movements are the examples chosen by the speaker; decades later their troublesome nature has done nothing but increase, confirming his concerns and Goethe's far-sightedness, today as then embodying the possibility of another science, founded on other choices and other values and yet not less rational and understandable. In order to set up a discourse going against consolidated commonplaces and rhetoric, we need to start from afar and ask a question that many would define as idle: how to conciliate the «fatal insight», highlighted by Beck and arising from the scientific adventure, with opposing claims formulated by a large part of its experts and leading figures.

Without beating about the bush, what is at stake is the very idea of reality: a world mechanically ordered, knowable through rational procedures and tools and existing quite apart from human action and intentions on the one hand; on the other, the issue of an unceasing task in affronting something beyond, out of scale even with respect to our remarkable abilities of comprehension, and in giving shape to its results. To better understand the latter, it is time we went back to Weber and his beautiful definition of culture, delving a bit deeper into his meaning. I believe it marks one of the most far-sighted efforts to define the human condition and touches on a great many of the (dis)qualifying aspects of the current order. What emerges from it at first glance is no longer a knowable world waiting for someone to discover its laws, but a difficult, delicate creation, a constant struggle to make sense of a «tiny part» of infinity that intrinsically possesses none, at least as immediately regards man. This is the first great fracture in the common sense that for so long has been an essential ingredient in our «finite section», to the point of intimately influencing the very language of knowledge: the idea of "research" presumes something already existent yet to be found, just like "discovery" and the rest of the baggage of investigative expressions. This is a belief originating long ago in the religious vision of the world when the gods, then God, had turned their hands to powerful cosmogonies, the outcome of which is what surrounds us, therefore rife with the sense willed by the creator and artfully hidden to test and mature his beloved children. Galileo, among the fathers of the Scientific Revolution, wrote in I/ Saggiatore (The Assayer) (1623) that «philosophy is written in this grand book, the universe, which stands continually open to our gaze. But the book cannot be understood unless one first learns to comprehend the language and read the letters in which it is composed. It is written in the language of mathematics, and its characters are triangles, circles, and other geometric figures without which it is humanly impossible to understand a single word of it; without these, one wanders about in a dark labyrinth».

Unveiling the magnificent natural book written by God was the task of the scientist. This idea has been at the basis of each successive cognitive effort, although in the meantime faith has withdrawn to other spheres and fewer and fewer have believed in the divine role. God has hidden himself so deeply within hearts as almost to disappear, yet the question on the pre-existing order for which he was responsible has not been asked. Meanwhile the new certainty sheltering it from undesirable doubts depended on the mechanistic interpretation of the universe, seen as a perfect machine whose working sooner or later would fall completely within our grasp; this would surely happen through the evolution of the calculus, discovered and perfected by Newton, which greatly helped mathematics to gain the aura that still surrounds it: it is the key to open the last lock to the treasure trove wherein lies the sceptre of control and the solution to the problems and difficulties afflicting humanity. As for any self-respecting machine, the instruction manual guarantees the user reliability and defined performance, allowing him to manage it as he likes for the ends he is seeking at any given time. There is no longer any trace of the machine's builder, but the evidence of the machine stays with us as does the dream of one day commandeering its course. However, if we stop to think, the removal of the problem does not constitute its solution: it merely enables us to continue along the road we have long been on, in an excellent example of paradigmatic inertia.

But here comes Weber; to the unasked question he provides an answer both courageous and terrible: it is vain to seek a pre-existing sense, since our 
world is only a «finite section of the meaningless infinity of events in the world, endowed with meaning and significance from a human perspective». These words resolve the great misunderstanding and reinvest man with the responsibility that he has so far shown himself incapable of accepting: what we thought we would find is in fact what we ourselves placed there, having constant care and maintenance of that portion of reality we had managed to retrieve from chaos and build up, «endowed with the capacity and the will to adopt a deliberate position with respect to the world, and to bestow meaning upon it». Culture is today understood mainly as being in clear opposition to Nature, being what is human as opposed to what is there through the work of another - whether demiurge, god, or impersonal mechanics. All said and done, it is there to be exploited. Few will bother to think that this is the umpteenth deceptive dichotomy, that both one and the other are terms of a continual to-and-fro in which all pre-exists and all is created at some point in its existence, not only in its planning but also in its thinkability as an object and in its admissibility to be part of the world; or in its reduction to that single dimension, as has been happening for a long time to our bodies. These are scarcely obvious dynamics, above all in the light of the current representation of the human being as rational, transparent and ever present to himself and to others, in particular in the assessment and pursuit of his own interest. From this point of view Weber himself cannot be considered quite guiltless.

As I already noted, both he and Simmel (the former more so than the latter) shared with Modernity this representation of the human being, a heroic vision but harbinger of problems and difficulties. The very generation and attribution of sense, an immense task, is something Weber believes to be conscious and voluntary, which makes it incomprehensible in some ways: who amongst us can seriously state to have consciously set hand to the sense of the world, when so often it puzzles us or seems inexistent? When we are convinced that it must have been here since the beginning, quite apart from our existence and our intentions, so much so that in contrast we think our existential condition to be absurd: the world has a sense, while I can find none in my life... The deliberateness Weber speaks of requires detailed discussion, since many of the primordial choices at the core of the Western paradigm date back to eras when consciousness and awareness were vastly different from how we are used to thinking of them today, often wrongly, calling upon heuristic and cognitive processes, where subjectivity - again as we understand it - played, at most, a marginal role. In the inclusive view we are trying to sketch here, that does not mean that whatever has to do with the generation of reality happens solely below the threshold of consciousness or in ways in which the latter is not fully involved. How can we otherwise account for the careful imagination that calls for change and the adaptation of the real to ideals it considers better and more worthy? Progress itself, Modernity's myth par excellence, can only be conceived of in the light of a malleability of the stuff of the world that its present definition as objective and radically separated from the cognitive, active subject reduces to a brutal instrumental intervention. In order to clarify this point, for the moment we will take as valid Weber's formulation and will try to understand it better.

\section{The Care of the World}

With this in mind, it is well to recall two key terms from the philosophical tradition, Realität and Wirklichkeit, in order to highlight an aspect of reality that would escape us without such terminological exactitude. Both in fact translate into English with "reality", but while Wirklichkeit refers to effective reality, that which exists and is taken for granted, the former refers to an inexhaustible potential; in other words it describes «the meaningless infinity of events in the world» Weber speaks of. This philosophical pair sets forth in another register the tension implicit in Weber's text: confronting a matrix infinity, limitless in its signifying potential but insignificant in itself - at least from man's point of view is the world that humankind has brought about since its appearance, everything that a myriad of cultures following one upon the other on earth have achieved in the different finite sections they have generated. In this light, Wirklichkeit appears to be formed by the whole array of the objective cultures, present and past, living and dead; and that is largely how it has been understood. Yet this is an interpretation strongly affected by the Nature/Culture dichotomy, therefore removing the former from the process and limiting the latter to the usual, more or less sophisticated list of discoveries and inventions, spiritual and material. What Weber has in mind is something else: the genesis of the finite section springs from deeper origins, from the selection of what may or may not be thought of or construed as a component part of reality; from the construction processes of what Fink was to call the «being-a-thing of things» (2016, p. 59), to which, post-Heraclitus, no-one has given much thought: «We are accustomed by a long tradition to make statements concerning beings. Beings lie before us; we experience, observe, investigate them. From our insight into their concrete content, we take the facts of the matter pertaining to them and formulate this in language. The thing becomes the "about-which" of our statements, becomes the underlying thing for our speech-which is about or on it» (Fink, 2016, p. 58). As Morin has underlined, there is also the «determination of master logical operations» (1999, p. 8), the preference given to a certain way to relate things: exclusioninclusion, disjunction-conjunction, implication-negation. 
It is only later on, after such crucial choices, that what we are used to considering the zero degree of the relationship with the world begins, the evidence of Being which imposes itself upon our investigation as independent and separated, and the construction of Nature as the indifferent environment in which man finds himself acting, by divine gift/punishment or by some evolutionary accident. Before acquiring the awareness of potentially being responsible or co-responsible for certain events - still today little understood, as the environmental issue dramatically demonstrates «threats [...] remained in essence "blows of fate" that assaulted human beings from "outside" and could be attributed to "external" gods, demons or nature» (Beck, 2009, p. 7): outside the ordered world of culture, the encircling walls, the confines of cultivated fields. If the proposal that I am formulating has any plausibility, I need at this point to explain how it was possible that the primordial choices disappeared from memory, that the idea of a safe haven within Realität only reappeared at the start of the twentieth century, yet without influencing in any way the vision of the world perhaps right up until today. One possible reading points to a weakness in the historical imagination recognized by Vico as fundamental to the understanding of man's journey down the ages: we project backwards the kind of awareness we are used to, the corresponding state of the reason and the current state of knowledge, thus failing to get the feel of what it was like to live in other times. We imagine how we would have done things, would have thought thoughts, and we guess that they must have done the same; so we get a biased version of the past that fits well within our frameset of reference. Moreover, there was no evidence of any founding gestures of such importance; and in any case, whoever would have thought that remote, undeveloped civilizations might be capable of them, had such an issue ever crossed their minds? Finally, the most remote traces indicated a continuity in knowledge beyond any reasonable doubt: this is the «long tradition» Fink speaks of.

The fact is, we had no idea how very remote our origins were and how very different they were from us! The discovery of the dizzying history of humankind 200,000 years from the appearance of modern Homo Sapiens, between 8,000 and 12,000 from the discovery of agriculture - is all too recent and still far from being metabolized: «lt is not a question of hypostasizing a redemptive primitivism, as many have done over the centuries, but of considering that our existence as humans has a much wider horizon than the one we name civilization, which wholly includes our repressed proximity to the animal» (Cavalli Sforza and Padoan, 2013, p. x). We should begin to take this into account and revise our deep-set convictions accordingly. It is true, from what was previously known, nothing could have justified the idea of a progressive, still on-going, creation of reality. And yet it is somewhere within our species' enigmatic journey that the first choices were made, before language and seminal subjectivity, when the tool for understanding the world was the image, myths and rites the strategies for bringing it to light and shaping it. Opening up these amazing panoramas with their discoveries, today's sciences have forced a revised narration of the human saga and an acknowledgement of the role, still central today, played by our poietic potential in knowing and caring for the finite section we inhabit. There is irony in the coincidence, nowadays, of a sudden, destabilizing opening out towards the farthest past, dramatically relativizing the tale of the triumphs of global civilization, and an entrenchment in the present. From the conquest of a new awareness of the concrete dimension sacrificed by modern tension between past and future (Maffesoli, 1979), this becomes the paradoxical ultimate line of resistance against that very erosion (Mongardini, 1993), the attempt to safeguard the epic of division on which Modernity is founded: «The asymmetry between nature and culture then becomes an asymmetry between past and future. The past was the confusion of things and men; the future is what will no longer confuse them. Modernization consists in continually exiting from an obscure age that mingled the needs of society with scientific truth, in order to enter into a new age that will finally distinguish clearly what belongs to atemporal nature and what comes from humans» (Latour, 1993, p. 71). Close in sense, past/future reproduces the nature/culture pair and as such comes to a crisis when everyday experience and the constant gathering of anomalies more and more clearly belie the device for definition and order that gave them sense.

This dynamic appears hardly surprising if we employ greater pathos in trying to understand what Weber says. In accord with the separation between intellect and passion typical of modern disenchantment, our «finite section» would be thought of as a piece of engineering, issuing from rational choices and procedures aiming to consolidate it, making it unassailable from what gives it origin - which is in fact what has been happening for centuries. If however we re-energize words, the first question is: how can infinity possibly be reduced? What method is required for the generation of the world and how to ensure its duration confronted with inevitable disaggregation? It appears almost obvious that as something finite, submerged in an infinite Becoming, is constantly subjected to torsions, pressures and the need to adapt and compensate, it would require similarly continuous maintenance and ceaseless dedication, lacking which rigidity and rupture would inevitably follow. The first obvious objection to this discourse regards the figure of the technician appointed for such a delicate task: if so few people are aware of it and of its crucial necessity, it is difficult to make out who has been dealing with it over the past few thousand 
years. Perhaps it is possible to find a suitable argument to oppose such an observation.

A role of this kind today would require at least a couple of degrees, specialization and certification courses of all kinds, and the unshakeable certainty of the actual possibility of its exhaustive description and transposition into procedures, and the range and typology of needful interventions. Such certainty, however, comes from the same idea of knowledge that we are criticizing, according to which reality is a finite set of data, however complex and stratified, and the knowledge concerning it is an ever more meaningful percentage of the whole. Reasoning on an infinite that remains unfathomable is another thing again. Knowing we are unable to know implies a caution unknown to recent human action, lost in its hybris of domination, the wary humility of the inhabitant of an archipelago of certainties laboriously built up, lost in the ocean described by Newton and Morin. Coping with the limits of our knowledge requires other strategies, tapping also different spheres from the clear Cartesian consciousness which has instead become the essential requirement for humanity. We have been teetering along this perilous brink for so long that we have forgotten about it, except in those rare, often life-changing epiphanies; this is perchance the geometric place of humanity, the contradictory balance between dimensions that reason can do no more than separate and that instead coexist in cycles and rhythms that we experience without understanding them: how can we cohabit with the awareness of our own finiteness, how can we cohabit with the perception of the impermanence of the world and of our own place within it? Behaving "as if" the problem did not exist, as if days were infinite and reality were solid and welcoming: "We fundamentally develop the capacity of not doubting, that is acting as if the world in which we live were absolutely certain" (Jedlowski, 1994, p. 35). It is a fundamental art, given what is at stake, yet requiring the specific wisdom of knowing when to give it up, in a ceaseless coming and going between distraction, illusion and clarity of mind: "The doubt that common sense suspends is the doubt that things can be "standardized" in different ways, i.e., that reality can be unlike what it appears to the mind bogged down in everyday activities. Common sense is a sort of mechanism aimed at keeping this doubt out of reach, at least until situations turn up for the management of which we must review what up to that point had been taken for granted» (Jedlowski, 1994, p. 37).

Everyone's life is an excellent gymnasium for practising "as ifs" because, before we reach the foundations of the real we are speaking of, there are many other levels of complexity interwoven in the finite section in which we live, of which we are unaware, and that are of no use for living pragmatically (or rather one usually thinks they are of no use, an idea sadly encouraged by today's political-media discourse), but whose existence we suspect at such times when common sense fails us and we need to set it up again with some trick such as "it's obvious", "everyone knows that..." and suchlike. In the argument we are developing, common sense offers a model for the conduct of the maintenance man of the real while being at the same time an integral part of it: we just have to hazard the hypothesis that its effect goes much deeper than we had thought so far. Jedlowski recalls Garfinkel's ethnomethodological experiments and the dramatic consequences they had on their unfortunate subjects: «They were apparently harmless exercises, but invariably they caused unease, anguish, anything up to panic in their subjects» (Jedlowski, 1994, p. 38). This was due to the fact that the "simple" request for a detailed explanation of the expression "to have a flat tyre" brings to light «the existence of a dense weft of assumptions that implicitly regulate our life, assumptions that we tacitly take for granted, the break-up of which plunges us into chaos» (Jedlowski, 1994, p. 38). The adverbs chosen by Jedlowski give a good idea of the somewhat undefined space required by the knowledge of not being able to know, where certainty and uncertainty transfigure one into the other like mirages: the tacit, the implicit, what is not expressed or in some cases what cannot be expressed are interwoven with what is said, with the evident, with the explicit; they fuel it and are fuelled by it in a reciprocal relationship - the Wechse/wirkung we have seen streaming between the inside and the outside of a door; it is a dynamically balanced flux made of deferments and regenerations, vastly different from the clear, distinct ideas that rule the model of an individual who has hardly any kinship with the tightrope-walker with whom man can be compared: «Existence as such is an acrobatic achievement, and no one can say with certainty what training provides the necessary skills to master this discipline" (Sloterdijk, 2013, p. 63).

The answer to the query of who is in charge of repairing the real therefore requires not only a reformulation of the idea of knowledge, but also of the idea of man, both central elements of that taken for granted that is so useful and so dangerous. The man as he is seems rather different from the man as he should be according to the current proposition, rationalistic, disenchanted, bit by bit shedding every dimension that is not conscious or calculating. He is a complex being, fragile yet resilient, living in an equilibrium continually perturbed by intimations springing from his innermost being and from the environment around him; the latter also being his own work and requiring constant commitment for its safeguard and enhancement. He frequently takes on these responsibilities obliviously, through routine and reliance on strategies having explicit meanings and implicit motives, like the famous Hopi rain dance (Merton and Barber, 2004) or the exclamations 
studied by Goffman (1981). Another theme turns up here: the relationship between non-intentionality and success and conversely the damage that excessive procedure-making and planning may have on the things of the world, of some interest at a time of hyperbureaucratizing such as the present. It is a theme in which the "as if" fits in nicely, since it allows a degree of spontaneity not otherwise obtainable and a privileged access to the tacit sphere of knowledge, which operates best in situations in which conscious reasoning may hinder rather than help, as the oriental disciplines teach, supported recently by important scientific discoveries (Goleman, 1995). It might even be possible to add to the debate the roguish idea that part of the destabilization and disharmony afflicting modern societies can be put down to the systematic depreciation of this basic part of human behaviour, reverberating through the quality of cohabitation and, as we suggest, through the very holding capacity of the real.

From this viewpoint, an essential ingredient of this is in fact the sharing of confidence in its having sense, the possibility that the appearance of doubt of its conventionality can be answered with a statement of significance that goes beyond everyday practical needs: «The aims for which we can act are multiple. What characterizes "common sense" is that in some way these too can be taken for granted. Common sense selects in the infinity of possible aims those that are plausible within the area of our culture, and supplies a framework of instructions on how we can organize our conduct to achieve them. But it presumes that these objectives are "sensible". In this regard, subjectivity is an anarchical principle. Strange questions pop up. "Why am I alive?", for example, or else "is what I am doing right for me?"» (Jedlowski, 1994, p. 22). The working of common sense closely recalls that of Kuhn's paradigm, in the normative choice of acceptable objectives and why they are acceptable: «One of the things a scientific community acquires with a paradigm is a criterion for choosing problems that, while the paradigm is taken for granted, can be assumed to have solutions. To a great extent these are the only problems that the community will admit as scientific or encourage its members to undertake. Other problems, including many that had previously been standard, are rejected as metaphysical, as the concern of another discipline, or sometimes as just too problematic to be worth the time. A paradigm can, for that matter, even insulate the community from those socially important problems that are not reducible to the puzzle form, because they cannot be stated in terms of the conceptual and instrumental tools the paradigm supplies» (Kuhn, 1996, p. 37).

Yet the "sensible» aims at any certain instant may not be sensible thereafter; it should be the task of thought and politics to choose new configurations for them, more suitable to the new circumstances. Even when this does not come about, however, the sense consciously chosen is founded on reservations and deeper layers on which to draw in continuation, up to the last regeneration that comes from the irrepressible tension between finite and infinite, allowing the very existence of the human cultural world while constantly putting it at risk. The agreement on the quality of the real is the primordial support on which the other dynamics rest; it is this that the present paradigmatic rigidity is submitting to a potentially damaging torsion. The construction of reality as separate and objective denies any possibility of intervening in its favour, radically lifting responsibility from each individual and making unthinkable his involvement in a process in which he could feel himself near others, united in a common task which is perhaps the very foundation of social cohesion, although at the level of dissimulation and unawareness of which we have spoken. Even without any specific thematization, the sensation of the active maintenance of the world and of the corresponding chance of modifying it as a consequence may be the root of selfesteem and commitment; it is the shortage of these that causes astonished and anguished lamentations and interrogation under the skies of the twenty-first century.

We have no idea of how many retreats into doubt the stuff of reality can tolerate before giving way and allowing infiltration of the chaos that always seeks dominance: «l believe life always tends towards chaos and that our system of tolerating anguish consists in producing a laboured, incessant attempt to tidy it up; but then we exchange our necessary memory box for the world, and we say that for nature men and women exist, men and animals, species hierarchically ordered, superior and inferior races, masters and slaves, soul and body, spirit and matter» (Cavalli Sforza and Padoan, 2013, p. 67). We have no idea how deep «the "evil eye" of the disenchanted» (Fink, 2016, p. 114) may reach before drying up the last sources of sense and interrupting the needful renewal of the finite section that exists and resists - another «open system» (Morin, 1993) - in relation to the infinite from which it springs. As in every cosmogony or later fantasy saga, we may hope that seeds remain of white trees or forgotten chalices to which we may have recourse, but the fear that the amputation of the roots has gone well beyond the sustainable is little more than formal optimism, and the sensation of the urgent need for a careful, conscious intervention is very much alive. A multidimensional intervention, yet cautious, courageous and calculated, since the umpteenth dichotomy it is intended to remedy - the clear-cut opposition between the hard, concrete sciences and the sciences of the spirit - proffers the fallacious belief that what concerns the latter is only a smoke-screen and plaything for irremediably unproductive people; it hides the basic practical correlation between Wirklichkeit and Realität, confining it within a metaphysical "elsewhere", whereas it is here 
and now: what we do not know that we do not know exists beside what has been defined as real, influencing it and conditioning it at every instant. The gap between the two is not an abstruse, distant issue: it is everyday non-alignment, perverse effects and deluded expectations, an incessant flaking away of the proclaimed solidity of the world.

Reducing infinity is a titanic move, a source of pride for humanity, yet it comes at a cost; it means honestly acknowledging limits and moderation in order to be able to oppose resistance to the Becoming. It is up to those who realize this to think of ways to make it come about so that - on the rim between consciousness and immediacy, between responsibility and poetry - we may continue to go forward. As Beckett wrote, to fail again. To fail better.

\section{BiBLIOGRAPHY}

1. Bachelard, G. (1994). The Poetics of Space [1958]. Boston: Beacon Press.

2. Beck, U. (2009). World at Risk. Cambridge: Polity Press.

3. Beck, U. (2016). The Metamorphosis of the World. Cambridge: Polity Press.

4. Berman, M. (2010). All That Is Solid Melts into Air. The Experience of Modernity [1982]. London, New York: Verso.

5. Bleicher, J. (2007). From Kant to Goethe. Georg Simmel on the Way to Leben. In Theory, Culture \& Society, 24 (6), 139-158.

6. Bohm, D. (1980). Wholeness and the Implicate Order. London, New York: Routledge.

7. Capra, F. (1975). The Tao of Physics. An Exploration of the Parallels Between Modern Physics and Eastern Mysticism. Boulder, CO: Shambhala.

8. Cavalli, A. (1998). Introduzione. In G. Simmel. Sociologia [1908] (pp. ix-xxvii). Torino: Edizioni di Comunità.

9. Cavalli Sforza L.L. \& Padoan D. (2013). Razzismo e noismo. Le declinazioni del noi e l'esclusione dell'altro. Torino: Einaudi.

10. Colli, G. (1993). La sapienza greca - III Eraclito [1980]. Milano: Adelphi.

11. Crespi, F. (1989). Azione sociale e potere. Bologna: II Mulino.

12. D'Andrea, F. (1999). Soggettività e dinamiche culturali in Georg Simmel. Roma: Jouvence.

13. D'Andrea, F. (2017a). Being Human. A few Remarks about Descartes' Cogito ergo sum. In Studi di Sociologia, 2, 135-146.

14. D'Andrea, F. (2017b). Of Cripples and Bags. Risk and the Stuff of Reality. Italian Sociological Review, 7 (2), 183-199.

15. D'Andrea, F. (2019). Simmel: Bildung as the Form of Subjectivity. Simmel Studies, 23 (1), 43-66.
16. De Simone, A. (2002). Georg Simmel. I problemi dell'individualità moderna. Urbino: Quattroventi.

17. Fink, E. (2016). Play as Symbol of the World and Other Writings. Bloomington and Indianapolis: Indiana University Press.

18. Gleick, J. (2011). The Information. A History, a Theory, a Flood. New York: Pantheon Books.

19. Goffman, E. (1981). Forms of Talk. Hoboken, N.J.: Blackwell.

20. Goleman, D. (1985). Emotional Intelligence: Why it Can Matter More Than IQ. New York: Bantam Books.

21. Hauter, K. (Ed.). (1922). Schulpädagogik Vorlesungen gehalten an der Universität Strassburg von Georg Simmel. Osterwieck-Harz: Zickfeldt.

22. Heisenberg, W. (1958). Physics and Philosophy: The Revolution in Modern Science. New York: Harper \& Brothers.

23. Holland. J.H. (1996). Hidden Order. How Adaptation Builds Complexity. New York: Basic Books.

24. Jedlowski, P. (1994). Il sapere dell'esperienza. Milano: Il Saggiatore.

25. Kauffman, S. (1995). At Home in the Universe. The Search for the Laws of Self-Organization and Complexity. Oxford-New York: Oxford University Press.

26. Kuhn, T.S. (1996). The Structure of Scientific Revolutions [1962]. Chicago, London: The University of Chicago Press.

27. Latour, B. (1993). We have never been modern. Cambridge, MA: Harvard University Press.

28. Maffesoli, M. (1979). La conquête du présent: pour une sociologie de la vie quotidienne. Paris: PUF.

29. Merton, R.K. \& Barber E. (2004). The Travels and Adventures of Serendipity: A Study in Sociological Semantics and the Sociology of Science. Princeton, N.J.: Princeton University Press.

30. Mongardini, C. (1993). La cultura del presente. Tempo e storia nella tarda modernità. Milano: FrancoAngeli.

31. Morin, E. (1993). Introduction à la pensée complexe. Paris: ESF.

32. Morin, E. (1999). Seven Complex Lessons in Education for the Future. Paris: UNESCO Publishing.

33. Popper, K.R. (1959). The Logic of Scientific Discovery [1934]. London, New York: Routledge.

34. Reale G. \& Antiseri, D. (2001). Quale ragione?. Milano: Cortina.

35. Scaglia, A. (2010). Max Weber e Georg Simmel: due diverse vie alla comprensione della modernità. In C. Corradi, D. Pacelli, A. Santambrogio (a cura di). Simmel e la cultura moderna - vol. 2: Interpretare $i$ fenomeni sociali (pp. 5-27). Perugia: Morlacchi.

36. Sheets-Johnstone, M. (2011). The Primacy of Movement. Amsterdam/Philadelphia: John Benjamins. 
37. Simmel, G. (1950). Fundamental Problems of Sociology. Individual and Society [1917]. In K.H. Wolff (Ed.). The Sociology of Georg Simmel (pp. 1-84). Glencoe: The Free Press.

38. Simmel, G. (1997). Bridge and Door [1909]. In D. Frisby and M. Featherstone (Eds). Simmel on Culture. Selected Writings (pp. 170-174). London, Thousand Oaks, New Delhi: Sage.

39. Simmel, G. (2010). The View of Life. Four Metaphysical Essays with Journal Aphorisms \{1918]. Chicago, London: The University of Chicago Press.

40. Sirost, O. (2005). Corpi sportivi e individuazione. In F. D'Andrea (a cura di). I/ corpo a più dimensioni. Identità, consumo, comunicazione (pp. 121-139). Milano: FrancoAngeli.

41. Sloterdijk, P. (2013). You Must Change Your Life. Cambridge: Polity Press.

42. Teodorani, M. (2007). Entanglement. L'intreccio nel mondo quantistico: dalle particelle alla coscienza. Cesena: Macro Edizioni.

43. Weber, M. (2012). The "Objectivity" of Knowledge in Social Science and Social Policy [1904]. In H.H. Bruun and S. Whimster (Eds). Max Weber. Collected Methodological Writings (pp. 100-138). London, New York: Routledge. 